\title{
The Influence of Artificial Body Fluids on Metallic Corrosion
}

\author{
Christopher M.A. Brett and loana Muresan \\ Departamento de Química, Universidade de Coimbra, 3004-535 Coimbra, Portugal
}

Keywords: artificial body fluids, saliva, steel, corrosion, passivation

\begin{abstract}
The influence of different artificial body fluids on metallic corrosion, all containing chloride ion, was investigated by measurements of open circuit potential, polarisation curves and electrochemical impedance on high speed steel, chosen owing to its high rate of corrosion. Two types of electrolyte fluid were studied, the first similar to saliva and the second to plasmatic serum and experiments were carried out over a period of immersion of $4 \mathrm{~h}$. Electrolytes similar to saliva were artificial saliva with and without lactic acid, and Glandosane ${ }^{\circledR}$ that contains sorbitol and Nacarboxymethylcellulose organic components. Similar to plasmatic serum were phosphate buffer saline (PBS) and Krebs-Ringer solution. It was found that the organic components in the fluids partially block the metal surface and reduce the corrosion rate. From the results obtained, an approximate order of corrosion rate was established as: Artificial saliva $\sim$ Glandosane $\sim$ KrebsRinger solution $<$ Artificial saliva without lactic acid $\sim$ PBS. It is demonstrated that the equivalence of these different body fluids as bathing solutions should not be assumed.
\end{abstract}

\section{Introduction}

Different artificial body fluids, all containing the aggressive chloride ion, can influence the metallic corrosion process. These effects, which have not been investigated, are particularly important since the solutions are often treated as equivalent media in biocorrosion studies, such as of dental amalgams. Body fluids, [1], are aqueous solutions of organic and inorganic substances including mainly the cations $\mathrm{Na}^{+}, \mathrm{K}^{+}, \mathrm{Ca}^{2+}$, and $\mathrm{Mg}^{2+}$, the anions $\mathrm{Cl}^{-}, \mathrm{HCO}_{3}{ }^{-}, \mathrm{H}_{2} \mathrm{PO}_{4}^{-}, \mathrm{SO}_{4}{ }^{2-}$ and those of organic acids. Saliva is an important biological fluid as it participates in the first step of digestion; it is a very complex mixture of substances with a $\mathrm{pH}$ between 6.4 and 7.0 , with $1-1.5$ litres being produced daily. Thus artificial salivas and body fluids have been developed for use in laboratory research.

In this work, metallic corrosion induced by two types of artificial biological fluid has been studied. The first type is similar to saliva and comprises artificial saliva (mainly chloride, hydrogencarbonate, sodium and potassium ions, lactic acid), artificial saliva without lactic acid, and Glandosane $^{\circledR}$ [2], that also contains sorbitol and Na-carboxymethylcellulose organic components as well as a higher concentration of chloride ion. The second type consisted of phosphate buffer saline (PBS) and Krebs-Ringer solution - solutions similar to plasmatic serum.

High speed steel was chosen as corroding metal because it readily undergoes corrosion, and data concerning its corrosion in pure chloride solution already exist [3]. A few corrosion studies of dental amalgams [4,5] and stainless steels [6] in similar media have been already done, but without any comparative study.

\section{Experimental}

Disc electrodes of M2 high speed steel, diameter $12 \mathrm{~mm}$, were sheathed with epoxy resin. Before each experiment they were polished with alumina down to $1 \mu \mathrm{m}$ particle size. The electrochemical cell also contained a saturated calomel electrode (SCE) as reference and a $\mathrm{Pt}$ foil auxiliary electrode.

The solution compositions per litre of solution were: 
(1) Artificial saliva (AS) (pH 6.5): $1.5 \mathrm{~g} \mathrm{KCl}, 1.5 \mathrm{~g} \mathrm{NaHCO}, 0.5 \mathrm{~g} \mathrm{NaH}_{2} \mathrm{PO}_{4}, 0.5 \mathrm{~g} \mathrm{KSCN}, 0.9 \mathrm{~g}$ lactic acid.

(2) Artificial saliva without lactic acid ( $\mathrm{pH}$ 5.5): as (1) without lactic acid in order to investigate the importance of the organic compound.

(3) Glandosane (pH 6.8): a commercial product used in stomatology $-0.84 \mathrm{~g} \mathrm{NaCl}, 1.2 \mathrm{~g} \mathrm{KCl}, 0.14 \mathrm{~g}$ $\mathrm{CaCl}_{2} \cdot 2 \mathrm{H}_{2} \mathrm{O}, 0.06 \mathrm{~g} \mathrm{MgCl}_{2} \cdot 6 \mathrm{H}_{2} \mathrm{O}, 0.34 \mathrm{~g} \mathrm{~K}_{2} \mathrm{HPO}_{4}, 30 \mathrm{~g}$ sorbitol, $10 \mathrm{~g}$ Na carboxymethylcellulose [2].

(4) Phosphate buffer saline (PBS) (pH 7.2): $8.0 \mathrm{~g} \mathrm{NaCl}, 0.2 \mathrm{~g} \mathrm{KCl}, 1.44 \mathrm{~g} \mathrm{Na}_{2} \mathrm{HPO}_{4}, 0.24 \mathrm{~g} \mathrm{KH}_{2} \mathrm{PO}_{4}$.

(5) Krebs-Ringer solution ( $\mathrm{pH} 6.9$ ): $6.98 \mathrm{~g} \mathrm{NaCl}, 0.36 \mathrm{~g} \mathrm{KCl}, 0.28 \mathrm{~g} \mathrm{CaCl}_{2}, 0.15 \mathrm{~g} \mathrm{MgSO}_{4}, 210 \mathrm{ml}$ phosphate buffer $\mathrm{pH}$ 7.4.

All solutions were prepared using Milli-Q ultrapure water of resistivity $>18 \mathrm{M} \Omega \mathrm{cm}$ and analytical grade reagents.

Open circuit potential and polarization curve measurements were carried out using a PAR 273A Potentiostat (EG\&G) controlled by M352 Corrosion Analysis Software which was also used for Tafel analysis. Impedance spectra were registered on a Solartron 1250 Frequency Response Analyser with a 1286 Electrochemical Interface using Zplot Software and ZSim CLNS software for simulation and fitting.

\section{Results and Discussion}

Measurements of open circuit potential, polarisation curves and electrochemical impedance were used to characterise the differences between the corrosion in the different media.

Open circuit potential. The open circuit corrosion potential measurements were carried out to examine the variation in time of the corrosion behaviour of the high speed steel under natural aerated conditions. All types of solution lead to large variations of potential over the first hour of immersion with tendency to a steady-state value over the following hours. An example is shown in Fig.1, where the sharp initial change in the negative direction in the solution with lactic acid due to the $\mathrm{pH}$ is followed by formation of oxide.

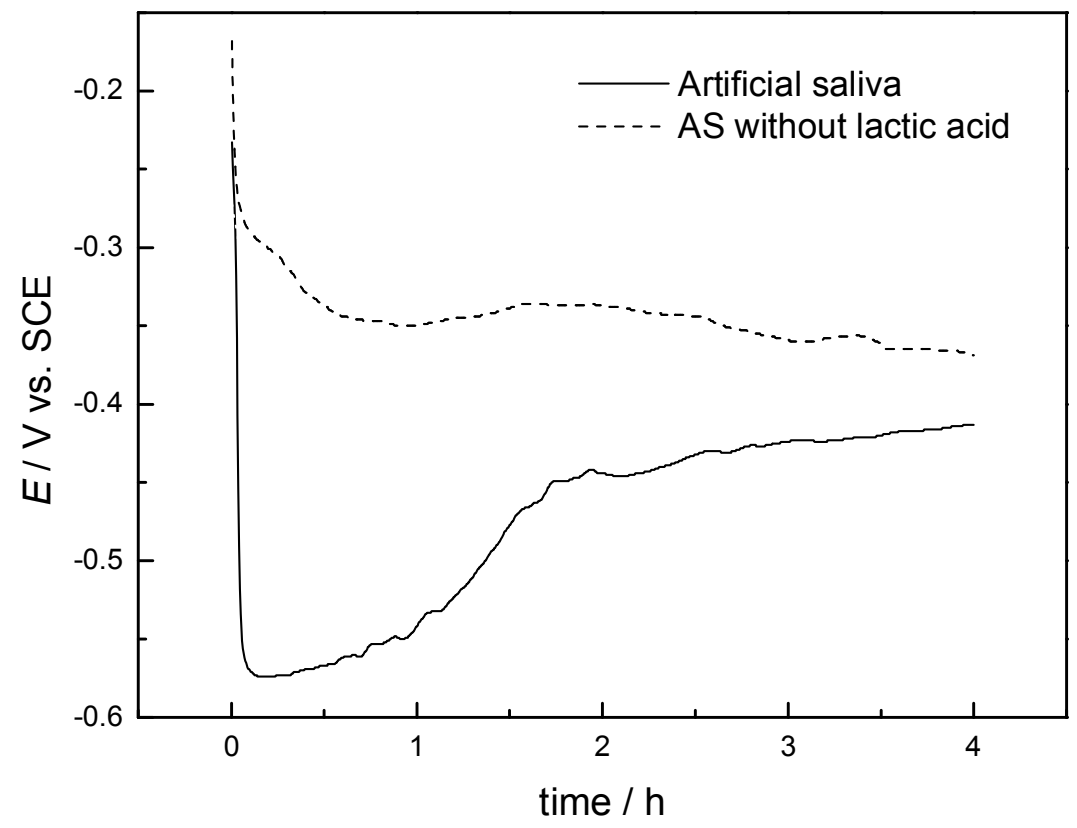

Fig.1 Open circuit corrosion potential measurements of high speed steel immersed in artificial saliva and artificial saliva without lactic acid. 
Without lactic acid, there is some initial slight blocking and variation in a negative direction, the OCPs in both solutions tending towards the same value. This indicates the effect of the presence of acids on increasing corrosion.

Table 1 Values of open circuit potential after immersion in various body fluids

\begin{tabular}{cccccc}
\hline & \multicolumn{5}{c}{ OCP / V vs. SCE } \\
\cline { 2 - 6 } Time after \\
\cline { 2 - 6 } immersion & $\begin{array}{c}\text { Artificial } \\
\text { saliva }\end{array}$ & $\begin{array}{c}\text { AS without } \\
\text { lactic acid }\end{array}$ & Glandosane & PBS & $\begin{array}{c}\text { Krebs- } \\
\text { Ringer }\end{array}$ \\
\hline $10 \mathrm{~min}$ & -0.574 & -0.317 & -0.376 & -0.380 & -0.406 \\
$1 \mathrm{~h}$ & -0.542 & -0.339 & -0.460 & -0.442 & -0.402 \\
$4 \mathrm{~h}$ & -0.413 & -0.363 & -0.511 & -0.538 & -0.434 \\
\hline
\end{tabular}

Values of the open circuit corrosion potential after different immersion times are collected in Table 1. It can be seen that the values and the variation with time is different in each case. These experiments were carried out several times and were reproducible.

Polarisation curves. An example of polarisation curves is shown in Fig.2. Tafel analysis showed that the potentials were similar to those obtained by open circuit measurements and corrosion currents were of the order of $\mu \mathrm{A} \mathrm{cm}^{-2}$.

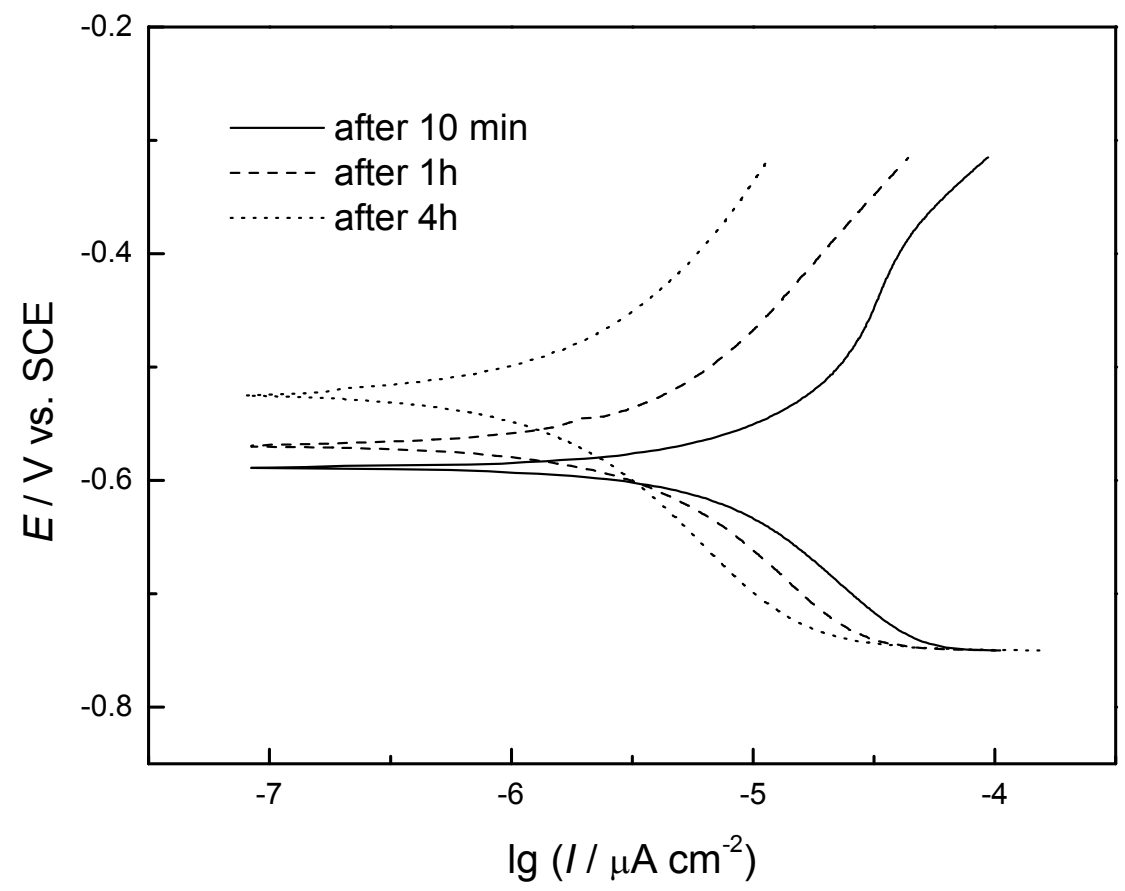

Fig.2 Polarisation curves for high speed steel immersed in artificial saliva solution

Table 2 gives values of the corrosion current after $4 \mathrm{~h}$ immersion for all fluids and demonstrates that the corrosion current in the absence of organic components is significantly higher despite indications from the value of the corrosion potential. This is particularly evident from artificial 
Table 2. Corrosion currents, $I_{\text {cor }}$, after $4 \mathrm{~h}$ immersion of HSS in various body fluids

\begin{tabular}{ccccc}
\hline \multicolumn{5}{c}{$I_{\text {cor }} / \mu \mathrm{A} \mathrm{cm}^{-2}$} \\
\hline $\begin{array}{c}\text { Artificial } \\
\text { saliva }\end{array}$ & $\begin{array}{c}\text { AS without } \\
\text { lactic acid }\end{array}$ & Glandosane & PBS & $\begin{array}{c}\text { Krebs- } \\
\text { Ringer }\end{array}$ \\
\hline 3.1 & 11.6 & 3.1 & 7.6 & 3.8 \\
\hline
\end{tabular}

saliva with and without lactic acid. Glandosane, containing polymer also has a low value as does Krebs-Ringer. The latter can be attributed to the presence of calcium aiding the formation of phosphates on the iron surface.

Impedance measurements. Impedance spectra were measured after various immersion times at the OCP at frequencies from $65 \mathrm{kHz}$ to $0.1 \mathrm{~Hz}$, and the results were modelled with an equivalent electrical circuit. The high frequency depressed semi-circle behaviour was modelled by a resistance in parallel with a constant phase angle element. The charge transfer resistances were of the order of $\mathrm{k} \Omega \mathrm{cm}^{2}$ and capacitances of the order of $\mathrm{mF} \mathrm{cm}^{-2}$. Values obtained paralleled the data obtained from polarisation curves and on the mechanism of the corrosion process, involving different relative contributions of pitting, surface blocking and oxide formation. Further details will be given elsewhere [7].

Surface analysis. Visual inspection and scanning electron microscopy showed that the density and size of the pits formed in the steel surface were dependent on the contacting electrolyte with the organic components reducing the amount of pitting. It also demonstrated, by comparison with [3], that not only $\mathrm{Cl}^{-}$is responsible for pitting but also the other inorganic electrolyte components.

\section{Conclusions}

The corrosion of high speed steel brought clearly into evidence the importance of the contacting solution on the rate of corrosion. It was shown that the presence of organic components in the fluid reduce the corrosion rate by blocking the metal surface. From this, an approximate order of corrosion rate can be proposed as: Artificial saliva $\sim$ Glandosane $\sim$ Krebs-Ringer solution $<$ PBS $<$ Artificial saliva without lactic acid.

This study demonstrates that in biomaterials studies it should not be assumed that all artificial body fluid media are equivalent.

\section{Acknowledgement}

I.M. thanks the European Union Socrates programme.

\section{References}

[1] A.J. Vander, J.H. Sharman and D.S. Luciano: The Mechanism of Body Function. Human Physiology, $6^{\text {th }}$ Ed. (McGraw Hill, NY, 1994).

[2] Dental Digest, Artificial Saliva, http://www.dentaldigest.com/otc (Odontos Publishing, 1996).

[3] C.M.A. Brett and P.I.C. Melo: J. Appl. Electrochem. 27 (1997) 959.

[4] B. Westerhoff, M. Darwish and R. Holze: J. Appl. Electrochem. 22 (1992) 1142.

[5] H.A. Acciari, E.N. Codaro and A. Guastaldi: Mater. Lett. 36 (1998) 148.

[6] J. Pan, C. Karlen and C. Ulfvin: J. Electrochem. Soc. 147 (2000) 1021.

[7] C.M.A. Brett and I. Muresan: in preparation. 